\title{
Towards Full-Fledged Inflation Targeting Monetary Policy Regime in Mauritius
}

\author{
Ashwin Madhou ${ }^{1}$, Tayushma Sewak ${ }^{2}, \operatorname{Imad}_{\text {Moosa }}{ }^{3}$, Vikash Ramiah $^{4}$ and Florian Gerth ${ }^{4, *}$ (D) \\ 1 Research and Economic Analysis Department, Central Bank of Mauritius, Sir William Newton Street, \\ Port-Louis 11328, Mauritius; ashwin.madhou@bom.mu \\ 2 School of Economics, The University of Adelaide, Adelaide, SA 5005, Australia; sewakt1@gmail.com \\ 3 School of Economics, Finance and Marketing, RMIT University, RMIT University, \\ Melbourne, VIC 3000, Australia; imad.moosa@gmail.com \\ 4 Faculty of Business, University of Wollongong in Dubai, Dubai P.O. Box 20183, United Arab Emirates; \\ VikashRamiah@uowdubai.ac.ae \\ * Correspondence: floriangerth@uowdubai.ac.ae; Tel.: +971-42781952; Fax: +971-42781800
}

Citation: Madhou, Ashwin

Tayushma Sewak, Imad Moosa,

Vikash Ramiah, and Florian Gerth. 2021. Towards Full-Fledged Inflation Targeting Monetary Policy Regime in Mauritius. Journal of Risk and Financial Management 14: 126. https:// doi.org/10.3390/jrfm14030126

Academic Editor: Chien-Chiang Lee

Received: 8 February 2021

Accepted: 12 March 2021

Published: 17 March 2021

Publisher's Note: MDPI stays neutral with regard to jurisdictional claims in published maps and institutional affiliations.

Copyright: (c) 2021 by the authors. Licensee MDPI, Basel, Switzerland. This article is an open access article distributed under the terms and conditions of the Creative Commons Attribution (CC BY) license (https:// creativecommons.org/licenses/by/ $4.0 /)$

\begin{abstract}
An increasing number of emerging and developing countries have adopted or are transitioning towards full-fledged inflation targeting (FFIT) as the main monetary policy framework to anchor inflation. In this paper, we explore the FFIT regime as a means for Mauritius to achieve stable inflation, anchor inflationary expectations and establish credibility in committing monetary policy towards price stability as its primary goal. This paper reviews and highlights issues experienced with the current monetary policy framework and the challenges in transitioning towards FFIT. Given that forecasting is central to FFIT, we develop a practical model-based forecasting and policy analysis system (FPAS) to support transition to FFIT, taking into account structural features and shocks that are specific to the Mauritius economy.
\end{abstract}

Keywords: inflation targeting; monetary transmission mechanism; forecasting; Mauritius

JEL Classification: C51; E31; E37; E52; F47; O23

\section{Introduction}

Despite adverse shocks to their economies, inflation has been fairly stable in many advanced and emerging market economies. This has been attributed, in part, to significant changes in their monetary policy frameworks - specifically, more flexible exchange rate regimes accompanied by inflation targeting (IT). Against this background, an increasing number of emerging and developing countries have adopted or are transitioning towards full-fledged inflation targeting (FFIT) as the main monetary policy framework to anchor inflation. In contrast to other monetary policy regimes, FFIT combines the choice of a nominal anchor with an institutional commitment that emphasizes transparency and accountability for the purpose of accomplishing the objective of enhancing the credibility and predictability of monetary policy. In addition to IT, other common monetary policy regimes are money and exchange rate targeting regimes. Under a money targeting regime, the central bank manipulates the chosen monetary aggregate in order to influence the price level. This is based on the finding that in the long run, the price level is influenced by monetary growth. This regime fell out of favor in most advanced and emerging economies due to an unstable relationship between money demand, output and prices resulting from structural changes in the economy. Under an exchange rate targeting regime, the central bank tries to ensure that nominal exchange rate stability vis-à-vis the currency of an anchor country via interest rate changes and direct foreign exchange interventions, thereby "importing" price stability from the anchor country. The disadvantage of this regime is the loss of monetary policy independence. The loss of monetary policy independence and possible currency crises is discussed in the works by Islam (2019) and Xu et al. (2018). 
Under an FFIT monetary policy framework, price stability is the sole ultimate objective with inflationary expectations acting as the intermediate target, while short-term interest rates serve as the operating target. Monetary policy is conducted through the public announcement of a quantitative point or a range of targets for inflation, with the explicit declaration of the central bank that it will pursue price stability as its primary goal, subordinating all other possible goals. New Zealand was the first country to adopt inflation targeting in 1990 and by 2014, 35 countries were using FFIT, including developed, developing and emerging countries. Currently, three African countries follow FFIT: South Africa (2000), Ghana (2007) and Uganda (2013). Several African countries (such as Kenya, Mauritius and Botswana) adopt elements of IT while retaining a policy role for the exchange rate and money targets. The empirical evidence indicates improved economic performance following the adoption of FFIT in terms of macroeconomic stability as assessed by the volatility of inflation, inflationary expectations, exchange rate and output (see, for example, Mishkin and Schmidt-Hebbel 2007; Carare and Stone 2006; Batini et al. 2005). For detailed discussion on the pros and cons of IT, see for example, Mishkin and Schmidt-Hebbel (2007) and Bernanke (1990).

Earlier studies on FFIT overly focused on advanced economies. Limited data and the problem of credibility and independence of the central bank in the majority of emerging and developing economies have precluded studies on the implementation and effectiveness of FFIT. However, a growing number of empirical studies have analyzed the impact and effectiveness of FFIT in these economies (for example, Alichi et al. 2010). In line with this recent trend, the aim of this paper is to review and highlight the experience with the current monetary policy framework in Mauritius. Specifically, we explore the challenges faced by Mauritius in transitioning to FFIT as a means to achieve stable inflation, anchor inflationary expectations and establish credibility with respect to monetary policy. Furthermore, given that forecasting is central to FFIT, the paper also develops a practical model-based forecasting and policy analysis system (FPAS) to support transition to FFIT, taking into account structural features and shocks specific to the Mauritius economy.

Prior research on Sub-Saharan African economies has established the link between monetary policy and inflation. For example, Baldini and Poplawski-Ribeiro (2011) emphasize the importance of monetary policy in the determination of price levels. They analyze 22 Sub-Saharan African countries during the period 1980-2005 and argue that for the majority of economies within the sample, there is a lack of anti-inflationary monetary policy strategies. For 19 Sub-Saharan African countries, Barnichon and Peiris (2008) analyze the link between the deviation of output from its trend, the deviation of money supply from its trend and inflation. The authors find that the central bank-driven money gap plays a major role in increasing prices. On the other hand, Holmes (2002) finds only limited effectiveness of monetary policies on inflation. These studies have set the foundation for our current study. The recent work by Morozumi et al. (2020) is another paper that discusses inflation targeting within developing countries. Their main conclusion is that IT is less efficient in low-income countries due to the relative lack of central bank independence. Their work differs from ours in the sense that we focus on a country where the central bank independence is pronounced and legally grounded, and therefore the findings must be different.

The effectiveness of inflation targeting on the African continent is a popular discussion in the literature. According to Heintz and Ndikumana (2011), a fixed rule for central bank behavior leads to an increase in transparency and accountability of policymakers and they concluded that inflation targeting has been effective for South Africa, but not for Ghana. Aron and Muellbauer (2007) study the case of inflation targeting in South Africa and find that the main economic variables have improved since its introduction. Notably, nominal interest rates and inflation have decreased, GDP per capita has increased and the volatility of GDP and inflation has decreased. Another paper by Bleaney and Francisco (2016) provides contradictory evidence in that inflation targeting has not been effective for neither South Africa nor Ghana. More recently, Bleaney et al. (2020) answer the question 
of why the Ghanaian economy still exhibits high inflation rates even though their central bank has committed to inflation targeting. They find that their monetary policy authority acts in a theoretically coherent way. However, fiscal dominance erodes the credibility of the central bank with economic agents failing to anchor inflation expectations towards the target inflation rate. The authors conclude that inflation rates would have been higher if the Ghanaian central bank did not commit to inflation targeting. Given this dispute in the literature, we test which of the competing results is valid by focusing on a different country in Sub-Saharan Africa.

Given the information above, there seems to be a consensus that monetary policy committed to inflation targeting leads to macroeconomic stability for advanced and developed countries. For emerging and developing economies, on the other hand, findings are not only scarce, but are also inconclusive. As a result, the aim of this paper is to shed light on the macroeconomic effects of the Mauritian economy following policy targeting to actively stabilize and anchor inflation. Furthermore, since previous research has focused on off-the-shelf partial-equilibrium models, it is of importance to analyze the macroeconomic environment from a general-equilibrium perspective. Consequently, this paper relies on a New-Keynesian macro model which takes the shocks and unique features of the Mauritian economy into account.

Our findings are, first, that contrary to conflicting and inconclusive findings for other sub-Saharan economies, IT unambiguously benefits the Mauritius economy by stabilizing inflation and therefore minimizing macroeconomic uncertainty. Second, a model-based forecasting and policy analysis system (FPAS) not only captures within-sample forecasts well, but also predicts out-of-sample economic effects accurately. Furthermore, on the way to FFIT, the Mauritius economy benefits from the superior quality of its institutions that contribute to enhancing credibility. However, the choice of a nominal anchor remains obstructed because policymakers' attention is shifted to secondary objectives. Fourth, for FFIT to reach its full potential, sub-Saharan economies need to uniformly follow the same targets of macroeconomic certainty through inflation stability. Last, the results remain robust to a different model specification, which models the Phillips Curve through the interaction between the Non Accelerating Inflation Rate of Unemployment (NAIRU) and the output gap.

The rest of the paper is structured as follows. In Section 2, we present a review of macroeconomic and monetary policy developments in Mauritius. Section 3 contains a discussion of the significance of FPAS for Mauritius, whereas Section 4 is devoted to a description of the FPAS framework and its applications to the economy of Mauritius. In Section 4 , we present the data and empirical results on the modalities of transitioning towards FFIT. Section 6 provides concluding remarks and policy recommendations.

\section{Mauritius: Inflation and Monetary Policy Developments}

Stylized facts on key macroeconomic variables are presented in Figure 1, with a particular focus on inflationary developments in Mauritius. The consumption driven nature of the Mauritian economy is evident from the GDP decomposition, as consumption accounts for approximately 57 percent of total GDP. In terms of exchange rate movements, depreciation of the rupee vis-à-vis the US dollar is observed as from end of 2014Q4. 

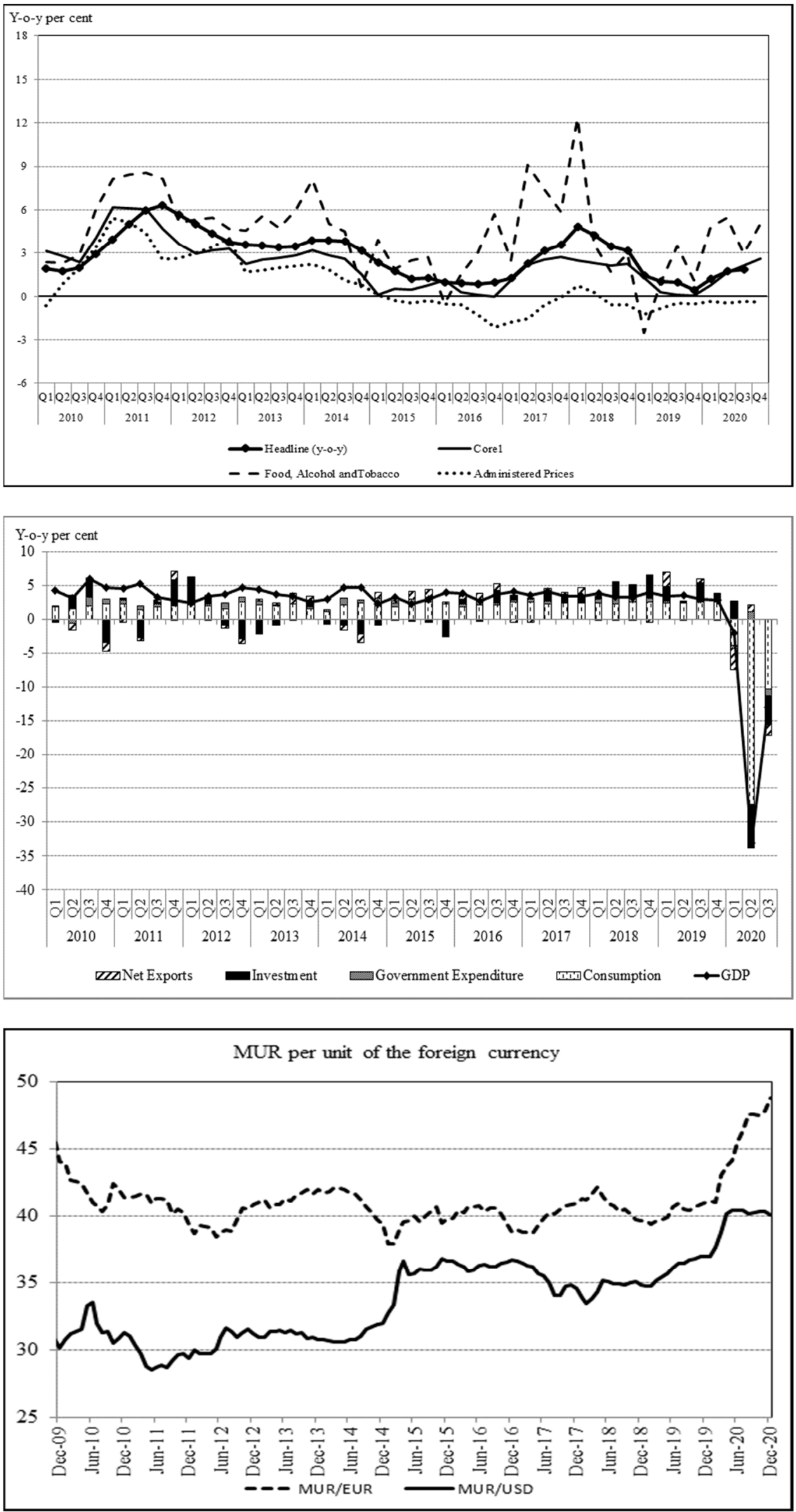

Figure 1. Macroeconomic Developments.

Inflation dynamics in Mauritius have been historically volatile in nature. The government of Mauritius reports two measures of inflation: headline and year-on-year. Headline inflation is reported by Statistics Mauritius, whereas year-on-year inflation is reported 
by the Bank of Mauritius. The headline inflation rate is calculated by comparing the average level of prices during a twelve-month period with the average level during the corresponding previous twelve-month period. The year-on-year inflation rate is calculated as the percentage change in the consumer price index (CPI) for a given month relative to the corresponding month of the previous year. Significant swings in inflation were observed during the period 2006-2008, which can be partly attributed to rising food and oil prices. The post-2009 period has been characterized by declining and subdued inflation. Food components (accounting for 27 percent of the consumer basket-excluding nonalcoholic beverages, food components account for 25 percent of the consumer basket-and consequently below the average of Sub-Saharan Africa), play a key role in inflationary developments in Mauritius. Seasonality plays an important role in determining the food price components, particularly vegetables (accounting for 16 percent share in food components). The idiosyncratic nature of the food components influences price dynamics in Mauritius to a large extent. The volatility in the consumer price index can be explained in terms of adverse climatic conditions and fasting seasons. Heavy rainfall in the December to January period of 2014, 2015 and 2016 led to substantial hikes in the price of vegetables due to an abrupt disruption in supply. The year-on-year core1 inflation rate (which excludes the food, beverages and tobacco components and mortgage interest on housing loans from the CPI basket) was -0.4 in January 2015, compared with the year-on-year inflation rate of 0.7 for the month. There was no sizeable change in the indices of beverages, tobacco and mortgage interest on housing loan. This is clear evidence of the impact of transitional shocks (that is, the effect of heavy rainfall on the price of vegetables). The first quarter of each year in Mauritius is dominated by religious festivals, whereby the majority of the Hindu population is dependent on vegetarian food only, thus boosting demand for a limited supply of vegetables. Therefore, supply side factors and the fasting season act as a compounding factor for increasing vegetable prices.

Mauritius might be one of the few countries in the world that grants a compulsory, non-performance-based end-of-year bonus to public and private sector employees. Despite the significant increase in the salary base in December, inflationary pressures remain subdued. The main explanation for this observation is that the end-of-year bonus is offset by the competitive end-of-year sales offered by retailers. Historically, Mauritius has had heavy reliance on imported food and fuel, which weighs considerably on the consumer price index. The normal assumption is that adverse movements in global food and fuel prices contribute to inflationary pressures. However, imported food and fuel are heavily administered through price controls and the domestic price stabilization program, limiting the pass-through of commodity price shocks to consumers. Basic goods (such as rice, cereals and flour) are subsidized by the Mauritian government. A government-owned body, State Trading Corporation (STC), regulates domestic fuel prices through the price stabilization program.

The historical perspective of the monetary policy framework in Mauritius has been reported in the literature, see Porter and Yao (2005), Heerah-Pampusa et al. (2006) and Tsangarides (2010) for a comprehensive background discussion. Furthermore, the speech of Governor Rameswurlall Basant Roi entitled "Monetary policy objectives in Mauritius and its operational framework since 1994", presented to major economic stakeholders on 3 December 2004, provides a historical view on the operational aspects of monetary policy (the speech is available under BIS Review 74/2004). Since 2007, teething issues have occasionally impinged upon the formulation of monetary policy by the monetary policy committee (MPC). As a result, key modifications have been made to the monetary policy framework to address those issues. Legislative amendments to the Bank of Mauritius Act 2004 (BOM Act 2004) have been made to strengthen the MPC composition. The MPC includes the BOM governor, two deputy governors, two persons appointed by the prime minister and three persons appointed by the minister of finance and economic development, see section 54(1) of the BOM Act 2004 for further information. In order to promote independence, transparency and the ethics of the MPC members, the BOM Act 
2004 was reviewed in 2011, requiring the MPC to publish a code of conduct to govern its meetings, and report to the board of directors of the BOM its compliance with the code of conduct on an annual basis (see section 54(2A) of the BOM Act 2004). Section 5(2)(a) of the BOM Act 2004 stipulates that the accepted range of the inflation rate during a given period, consistent with the pursuit of a price stability objective, shall be determined with the concurrence of the minister of finance. However, an explicit inflation target has not yet been officialized.

Endogenous and exogenous shocks have hindered the proper functioning of monetary policy in Mauritius. Since early 2009, the sustained disconnect between BOM's policy rate, the key repo rate (KRR) and the interbank rate has become more apparent, rendering the monetary transmission mechanism quasi inexistent (Figure 2). According to Mauritian authorities, the principal justification for the weak monetary transmission mechanism is the presence of excess liquidity on the domestic money market (Figure 2). Amongst others, special purpose funds deposited in commercial banks by government officials, building of international reserve buffers and the changes in the government debt mix are arguably the main reasons put forward for explaining the presence of excess market liquidity. There has been a shift in the composition of government debt between 2009 and 2014, with domestic borrowing declining by $12.5 \%$, paving the way for an increase in foreign borrowing by $36 \%$. This change can be explained by plunging global interest rates in the aftermath of the global financial crisis (GFC), thereby rendering foreign borrowing as a seemingly cheaper alternative for the Mauritian government.
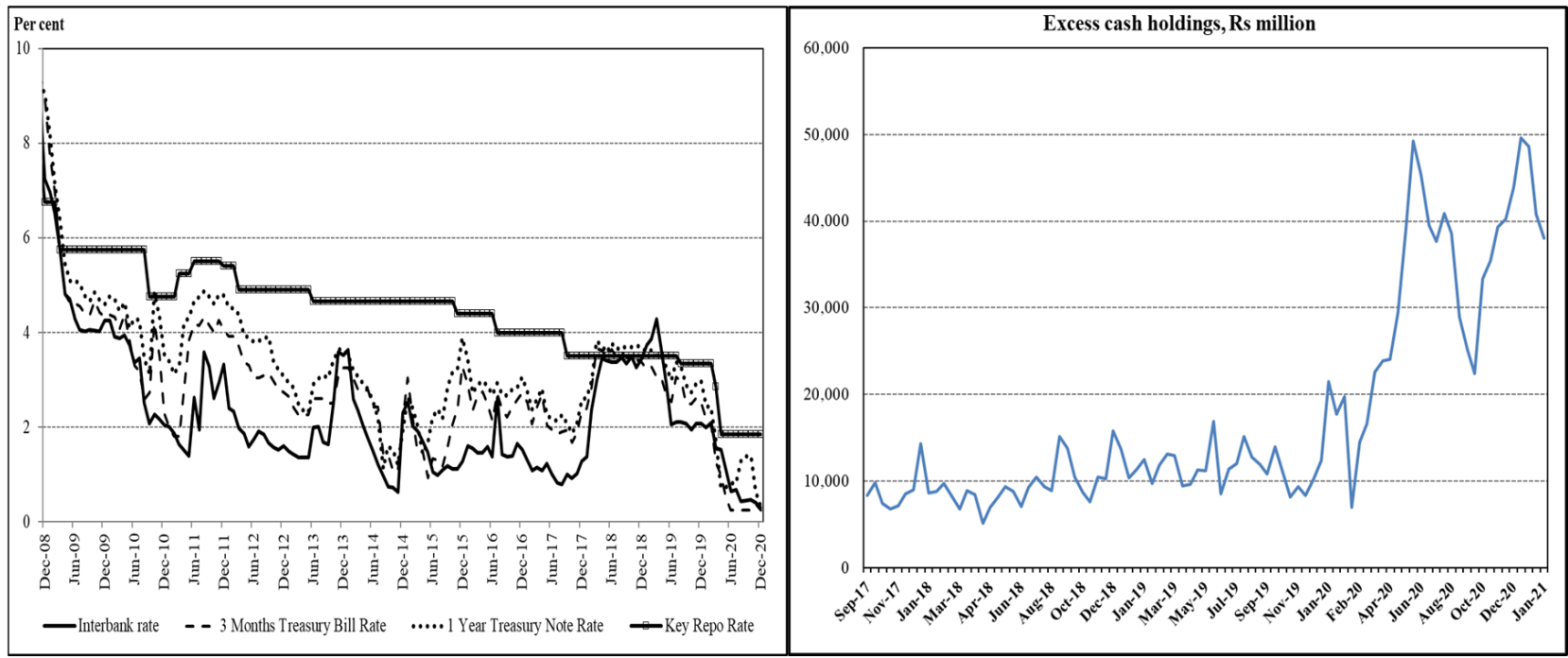

Figure 2. Monetary Transmission Mechanism and Excess Cash Holdings.

The GFC also hampered external demand through the tourism and manufacturing sectors. Faced with dwindling receipts, the Mauritian authorities launched special lines of credit, denominated in euros, to provide financial assistance to vulnerable sectors. Monetary policy followed suit as successive emergency MPC meetings led to significant monetary policy easing, with a fall of 250 basis points in the KRR between 2008Q3 and 2009Q1. An accommodative monetary policy stance has been maintained, with substantial policy rate cuts amid the economic damage in key sectors such as tourism, retail and manufacturing, associated with the COVID-19 pandemic.

\section{The Significance of FPAS for Mauritius}

In the light of external shocks (food, fuel crisis and the GFC) and the consequent volatility in inflationary developments in the 2000s (on average, headline inflation was $7.6 \%$ in the $1990 \mathrm{~s}$ and $5.9 \%$ in the $2000 \mathrm{~s}$ ), the obvious question that arises is whether or not the anchoring of inflationary expectations has been a success. Figure 3 presents 
headline inflation and responses of the 1-year ahead inflation expectation surveys over the period September 2010 to January 2021. Surveys of inflationary expectations are run on a quarterly basis and target approximately 50 market participants. The response rate hovers around $90 \%$.

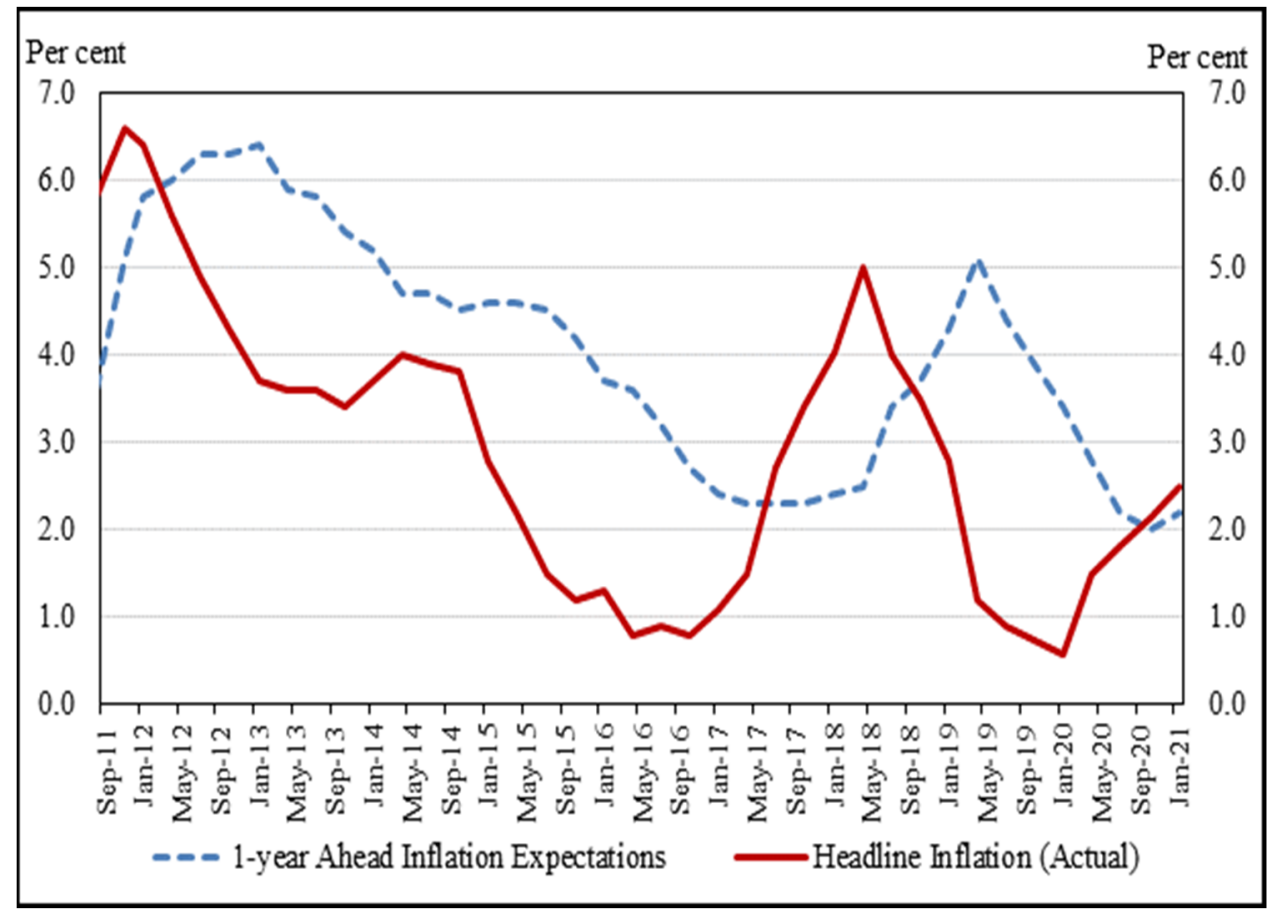

Figure 3. Inflationary Expectations.

Interpretation of anchored inflationary expectations is a matter of debate. The lack of consensus on anchored inflationary expectations is more prevalent in countries where an explicit inflation target does not exist, as is the case in Mauritius. Since 2011, only the directional movements of inflationary expectations have been tracked successfully by monetary policy actions, harboring the risks of deflation in cases where inflationary expectations are not well anchored.

The enactment of the BOM Act 2004 has channeled focus towards the maintenance of price stability through appropriate monetary policy responses. However, suitable monetary policy responses rely on the ability to be forward-looking, with the forecast inflation rate as the policy target while the interest rate serves as the operational target. Deviations from the policy target are generally justified and the necessary monetary policy decisions (through the MPC) have to be taken to bring inflation back to the implicit or explicit target. Presently, inflation targeting "lite" (ITL) is BOM's preferred monetary policy regime-as such, only specific features of inflation targeting have been embraced, such as MPC composition and model-based forecasts.

Several central banks in the region have been using the IMF's prescribed forecasting and policy analysis systems (FPAS) — the BOM is no exception to the rule. Kenya and Botswana are active users of FPAS. The implementation of FPAS is still at an initial stage for Tanzania, Uganda, Rwanda, Burundi and Mozambique. The key advantage of FPAS is its ability to facilitate policy analysis and provide advice on monetary policy actions to decision-makers, see Andrle et al. (2013) and Laxton et al. (2009) for FPAS implementation in IFT central banks. Despite a simple but transparent framework, FPAS captures the core structure of the economy and can help shape policy discussions. Scenario-building can help identify risks to the baseline forecasts and enable a proactive policy approach in response to the materialization of these risks (see Berg et al. (2006)). However, only the most relevant scenarios are considered in this paper. 
The application of FPAS to the Mauritian case has not been without any controversy. The distorted monetary policy transmission mechanism and the absence of an explicit inflation target have rendered the use of the FPAS framework more challenging, thus raising skepticism about the reliability of monetary policy decisions in influencing real economic variables. Despite the inherent issues or difficulties associated with the use of FPAS, its benefits outweigh the weaknesses. Once the FPAS framework is perfected and calibrated to reflect the dynamics of the domestic economy (parameters, trends and shocks), the value-added FPAS results can provide the prevailing storyline of the Mauritian economy and assist in monetary policy decision-making. Rather than focusing on the difficulties associated with employing FPAS, the Mauritian experience should be seen as an opportunity to improve and facilitate forward looking monetary policy formulation.

\section{FPAS Framework and Its Application}

Since 2012, reduced-form new-Keynesian open economy models have been operational in Mauritius. Their simplistic structure and economics-centric approach to monetary policy analysis have rendered the reduced-form new-Keynesian models, such as FPAS, popular across inflation-targeting central banks (Laxton et al. 2009). See O'Connell (2011) for a discussion on the applicability of the New-Keynesian model on predicting low-income countries. Compared to Real Business Cycle (RBC) models, new-Keynesian models take price and wage stickiness into account in order to capture macroeconomic features. Without allowing for these rigidities, the model would not be able to capture the cyclical fluctuations of the Mauritian economy because the labor market would clear instantaneously, a finding which the data do not support. Furthermore, purely RBC models do not allow for the role of the monetary policy authority and are, from a technical standpoint, inappropriate. On the other end of the spectrum, contrary to our model, Keynesian models are not micro-founded and are of partial equilibrium nature liable to ad-hoc assumptions. Since it is our interest to study the overall effects of the economy Keynesian models would be unsuitable. Furthermore, the Keynesian theory emphasizes the dominance of hysteresis in concluding macroeconomic effects, something that has been widely contested in the economic world. The FPAS model is intended to capture the dynamics of a small open economy by integrating forward looking aggregate demand, aggregate supply and lags in different monetary transmission channels. Exogenous shocks are quantified through US and Eurozone CPI, output gap and interest rate developments. Changes in external demand and foreign interest rates are assumed to be transmitted through exchange rate movements, eventually impacting domestic demand and inflation.

The FPAS framework captures four principal facets of an open economy through the investment-saving equation (IS), a modified Philips equation (PC), the uncovered interest rate parity equation (UIP) and a monetary policy rule (the Rule). For an overview of the standard FPAS model see Berg et al. (2006). It is important to point out that the FPAS framework lays much emphasis on trends and gaps, whereby the variables in the FPAS equations are expressed as gaps. The gap terms are quantified as deviations of the actual values from trends where trends and deviations are estimated by using the Kalman filter.

The four main building blocks are described below. The output gap equation (IS) is specified as:

$$
y_{g a p}=\beta_{\text {lag }} \text { ygap }_{t-1}-\beta_{R R g a p} R R g a p+\beta_{\text {Zgap }} Z g a p+\beta_{F g a p} y g a p_{t}^{\text {Fgap }}+\beta_{F I} F I_{t}+\varepsilon_{t}^{\text {ygap }}
$$

where ggap $_{t}$ is the output gap, RRgap is the real interest rate gap, Zgap is the real exchange rate gap, ygap Fgap is the output gap of the Eurozone, FI is the domestic fiscal impulse, $\beta$ is the parameter attached to each of the variables, and $\varepsilon^{y g a p}$ is the error term.

The inflation equation (PC) is specified as

$$
\pi_{t}=\gamma_{l a g} \pi_{t-1}+\left(1-\gamma_{l a g}-\gamma_{p m}-\gamma_{p m c}\right) \pi_{t+1}+\gamma_{p m} \pi^{p m}+\gamma_{p m c} \pi^{p m c}+\gamma_{y g a p} y g a p_{t-1}+\gamma_{Z g a p} z g a p_{t-1}+\varepsilon_{t}^{\pi}
$$


where $\pi_{t}$ is the year-on-year inflation rate, $p m$ is import prices, $p m c$ is the import prices of commodities, ygap is the output gap, zgap is the real exchange rate gap, $\gamma$ is the parameter attached to each of the variables and $\varepsilon^{\pi}$ is the error term. An alternative specification for the PC is examined. Following the referees' suggestions, we also use an alternative model which, instead of using inflation and the output gap as a proxy for unemployment, uses the Non Accelerating Inflation Rate of Unemployment (NAIRU) and potential output as a proxy for the Phillips Curve, see Appendix A. The extended model is in the spirit of Madhou and Sewak (2019), Saman and Pauna (2013) and Alichi (2015). However, the findings do not materially change and the qualitative conclusions remain the same. One of the reasons might be that in developing countries the correlation between the unemployment rate and inflation is significantly lower than in developed countries like the United States. For further discussion see Madhou and Sewak (2019).

The exchange rate equation (UIP) is

$$
z_{t}=\alpha_{z}\left(z_{t+1}-\frac{R S_{t}-R S_{t}^{f}-\rho^{*}}{4}\right)+\left(1-\alpha_{z}\right) z^{t a r}+\varepsilon_{t}^{z}
$$

where $z_{t}$ is the real exchange rate, $R S$ is the domestic nominal interest rate, $R S^{f}$ is the nominal interest rate in the US, $\rho^{*}$ is the domestic risk premium, $z^{\text {tar }}$ is the assumed exchange rate target, $\alpha$ is the parameter attached to each of the variables, and $\varepsilon^{z}$ is the error term.

Monetary policy is represented by the Taylor Rule, which is expressed as

$R S_{t}=\delta_{R S l a g} R S_{t-1}+\left(1-\delta_{R S l a g}\right)\left(R R_{t}^{*}+\pi 4_{t+1}+\delta_{\pi \text { Dev }}\left(\pi 4_{t+1}-\pi_{t+1}^{t}\right)+\delta_{\text {ygap }} y g a p_{t}+\varepsilon_{t}^{R S}\right.$

where $R S_{t}$ is the nominal interest rate, $R R^{*}$ is the equilibrium real interest rate, $\pi 4_{t}$ is expected inflation, $\pi^{t}$ is the inflation target, ygap is the output gap, $\delta$ is the parameter attached to each of the variables, and $\varepsilon^{R S}$ is the error term. An interesting extension to this model would be to consider the effect of negative interest rates and/or quantitative easing on the economy. For further discussion, see Khoury and Pal (2020) and Feldkircher and Huber (2018).

\section{Data, Parameters and Impulse Responses}

The model is estimated by using monthly and quarterly data for the period 2000 to 2020. Time series data were obtained from the Bank of Mauritius and the Central Statistics Office, covering key macroeconomic variables such as GDP, inflation, exchange rate, interest rate and fiscal balance. The three-month Treasury bill is used as a proxy for the nominal interest rate. The interbank rate was previously used as a proxy for nominal interest rate. With the prevailing excess liquidity problem and the relatively sluggish interbank market, the three-month Treasury bill rate proved to be a better proxy than the interbank rate for forecasting purposes. The selected variables are transformed into quarterly frequency and seasonally adjusted by using the X13 filter. The trends are extracted by using the Kalman filter and gaps are identified as deviations from trends. The foreign block and forecast values of key foreign variables are captured by data retrieved from the Mantis database which can be accessed through the OGResearch website on a subscription basis.

The estimation of parameters relies on cross-country observations, experience with historical data and calibration techniques (ordinary least squares regression and Bayesian regression). Bayesian estimation is deemed to be more appropriate for calibrating parameters. However, due to a significant change in the trend of the real exchange rate at the start of 2015, the use of Bayesian estimation is considered inappropriate at this stage. The intrinsic characteristics of the Mauritius economy as well as monetary and fiscal policymaking are endogenous in the formulation of parameter values. There is a substantial body of literature on the identification, rationalization and selection of parameters (Peiris et al. 2011; Dizioli and Schmittmann 2015). 
In the output gap equation, the $\beta$ parameters are fixed based on the level of inertia in the real economy, the observed experience on the effectiveness of fiscal and monetary policy transmission mechanisms, and the openness of the economy. More specifically, the level of economic activity is deemed to be more responsive to fiscal impulses compared to the lower calibrated impact of the monetary policy stance. In view of heightened volatility in domestic output, the level of persistence in the model has been moderated. Being a small open economy, the intrinsic characteristic of Mauritius and trends in the economic developments of its partners have been factored in by calibrating $\beta_{\text {Fgap }}$ and $\beta_{\text {Zgap }}$ at 0.3 and 0.2 , respectively.

In the PC equation, less importance has been attributed to import prices, as price developments are mostly dominated by local food prices. $\gamma_{l a g}$, which is theoretically the slope of the Phillips Curve, reflects the sacrifice ratio prevalent in Mauritius. It is the real cost of inflation as it shows the loss of output that would need to be endured in order to reduce the inflation rate by 1 percentage point. Exchange rate pass-through is assumed to be low, reflecting the frequent intervention of the BOM in the foreign exchange market. A higher weight is placed on forward-looking expectations, vis-à-vis adaptive expectations whereby adjustment is made according to previous expert errors. The economy is therefore taken to be more of a "speedboat" type, meaning that decisions of the MPC would have a more considerable impact on current inflationary pressures, as compared to a model entailing slow convergence on the prospected trajectory.

The UIP equation is a modified version of the canonical UIP, as it takes into account the existence of an assumed exchange rate target created by the intervention of BOM in the foreign exchange market. A higher weight is placed on the exchange rate target relative to forward-looking expectations and interest rate divergences.

The Taylor Rule block reflects a high level of persistence in nominal interest rates, indicating a "wait and see" policy approach. Given the dual mandate of the BOM (Section 4 of the BOM Act 2004) to maintain price stability whilst ensuring balanced growth, a weight of 0.5 is assigned to the output gap and the deviations of inflation from its target.

In view of the growing success of FFIT in taming macroeconomic volatility, many emerging and developing countries have demonstrated interest in the implementation of FPAS as a policy tool. This makes it possible for us to compare the parameter values of peer economies for a broad overview of the requisites for a future re-calibration process. Common practice involves a combination of Bayesian estimation techniques with an optimal rule that minimizes output, price and exchange rate volatilities. Table 1 provides a comparison of the parameter values included in the four building blocks for Mauritius vis-à-vis Sri Lanka, Kenya and Vietnam.

Table 1. Parameter Values of Mauritius Compared to Sri Lanka, Kenya and Vietnam.

\begin{tabular}{|c|c|c|c|c|c|}
\hline & \multirow{2}{*}{ Parameters } & \multicolumn{4}{|c|}{ Posterior Estimates } \\
\hline & & Mauritius & Sri Lanka & Kenya & Vietnam \\
\hline \multirow{5}{*}{ Philips Curve } & $\gamma_{l a g}$ & 0.30 & 0.01 & - & 0.22 \\
\hline & $\gamma_{p m}$ & 0.15 & \multirow{2}{*}{0.72} & 0.05 & - \\
\hline & $\gamma_{p m c}$ & 0.03 & & - & - \\
\hline & $\gamma_{\text {ygap }}$ & 0.45 & 0.45 & 0.50 & 0.27 \\
\hline & $\gamma_{Z g a p}$ & 0.05 & 0.04 & - & 0.34 \\
\hline \multirow{5}{*}{ Output gap } & $\beta_{\text {lag }}$ & 0.20 & 0.09 & 0.60 & 0.56 \\
\hline & $\beta_{\text {RRgap }}$ & 0.05 & 0.05 & 0.15 & 0.10 \\
\hline & $\beta_{\text {Zgap }}$ & 0.20 & 0.04 & 0.60 & 0.09 \\
\hline & $\beta_{\text {Fgap }}$ & 0.30 & 0.19 & 0.15 & 0.13 \\
\hline & $\beta_{F I}$ & 0.15 & 0.22 & - & - \\
\hline \multirow{3}{*}{ Taylor Rule } & $\delta_{\text {RSlag }}$ & 0.75 & 0.68 & 0.8 & 0.49 \\
\hline & $\delta_{\pi D e v}$ & 0.50 & 1.31 & 1.4 & 1.53 \\
\hline & $\delta_{\text {ygap }}$ & 0.50 & 0.48 & 0 & 0.12 \\
\hline Uncovered Interest Parity & $\alpha_{z}$ & 0.20 & 0.84 & 0.75 & 0.17 \\
\hline
\end{tabular}

Sources: Peiris et al. (2011), Andrle et al. (2013), Dizioli and Schmittmann (2015). 
Differences in economic structures imply that parameter values as well as equation components tend to diverge across countries. For Sri Lanka, an extra term is included in its output gap equation to capture the bank lending channel, whereas in the case of Kenya two versions of the Philips curve are used to account for food and non-food inflation, respectively. Coefficients for Vietnam bear the least resemblance to Mauritius due to divergent economic characteristics, except for the UIP equation where both Mauritius and Vietnam have exchange rates that react more quickly to forward expectations relative to interest rate differentials. Similar to the seasonal impact of rising food prices in Mauritius, Kenya remains vulnerable to international and local supply food shocks that have augmented price volatility. Whilst $\gamma_{\text {lag }}$ of 0.3 in Mauritius caters for inertia, exposure of Kenyan prices to food shocks is captured through a lead parameter of 0.5. Conversely, both Mauritius and Sri Lanka are characteristically open economies. Yet, Mauritius's growth is posited to be more driven by external demand conditions due to higher estimates of $\beta_{Z \text { gap }}$ and $\beta_{\text {Fgap }}$, compared to Sri Lanka which places more importance on fiscal spending.

The Taylor Rule block shows similarity in the persistence level of policy rates for Mauritius, Sri Lanka and Kenya, although an exchange rate variable is incorporated in this equation for Sri Lanka and Kenya. Furthermore, Mauritius has adopted a different stance, placing equal weights on the inflation and output gaps, whilst optimal rules suggest higher weights on inflation deviations to counter macroeconomic volatility.

Once the model has been calibrated to the country's specificities, impulse responses can be used to test the validity and linkages of the four equations. Through pictorial description, impulse responses serve as a robustness check of the model. Directional movements and the speed of adjustment can also be assessed for each of the core macroeconomic variables: real GDP, inflation, exchange rate and interest rate.

The impulse response based on a contractionary monetary policy is displayed in Figure 4. The impulse response tests show that a contractionary monetary policy exhibits the expected effect of declining real GDP, followed by a declining inflation rate. These results satisfy economic rationale and desired patterns. A further check of the robustness of the model is shown through variables that tend to their target values whilst gap variables eventually converge on zero.
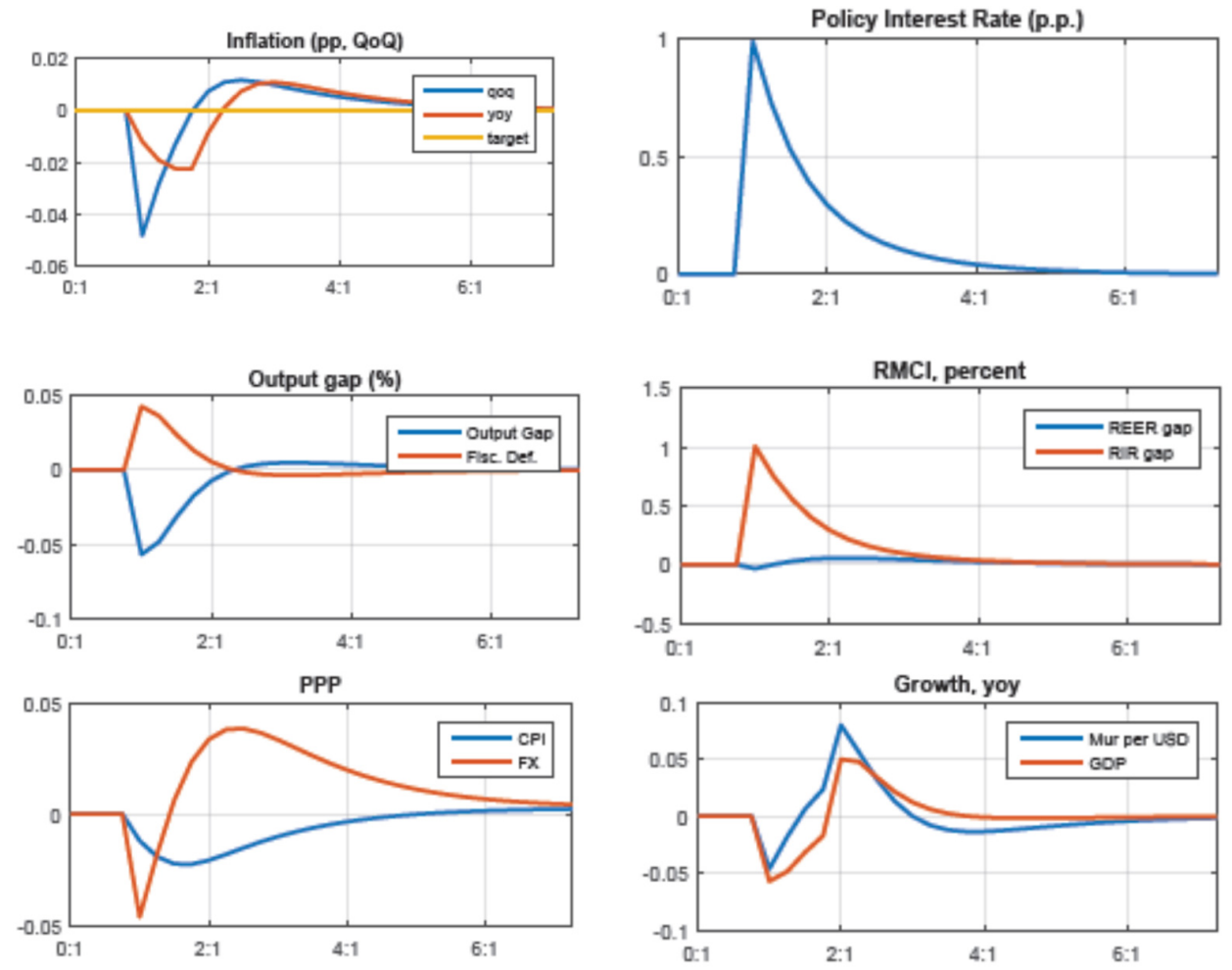

Figure 4. Impulse Responses of Monetary Policy Shock. 
A well-designed and calibrated FPAS model can assist monetary policy formulation and help contain wide fluctuations in inflation. Derivation of baseline scenario over the medium term is one of the key functions of the FPAS model. Figure 5 shows the projections of real GDP, exchange rate and nominal interest rate for the period 2021Q1 to 2024Q4.

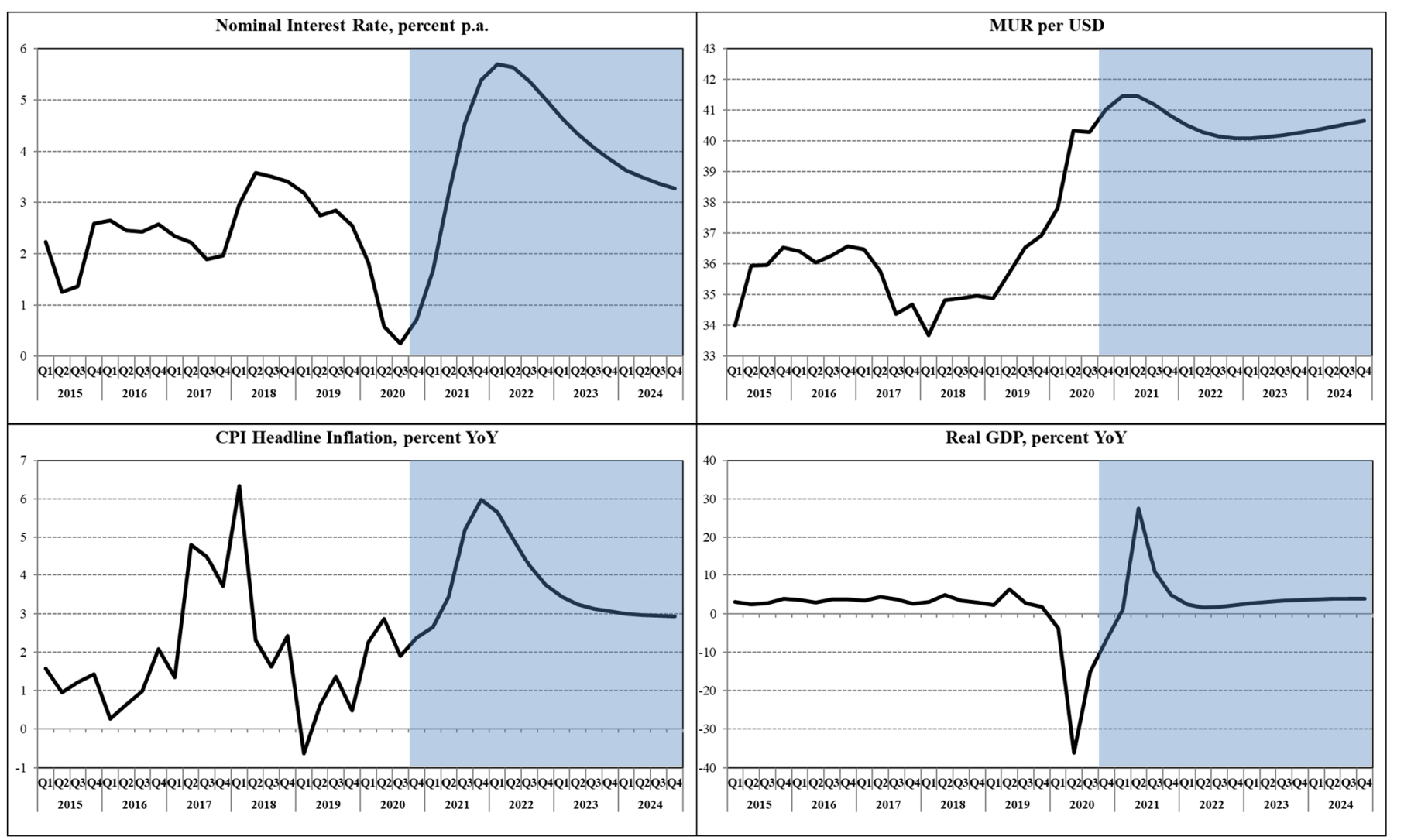

Figure 5. Baseline Macroeconomic Projections.

The estimated model can be used under specific shock scenarios to determine their respective impacts on selected macroeconomic variables and to assess upside or downside risks to baseline forecasts. For this purpose, two stress scenarios are conducted: an increase in domestic food prices and an adverse change in external demand. The choice of the two stress scenarios is based on (i) seasonal food price shocks in Mauritius, and (ii) heavy reliance on the exports of goods and services. As a result of the food price shocks in early 2020, the increase in domestic CPI in 2020Q1 and 2020Q2 is followed by a hike in interest rates, eventually leading to a decline in real GDP. Figure 6 shows the interrelationship among core macroeconomic variables in the aftermath of a surge in inflation. Furthermore, unfavorable external demand conditions exert a negative impact on exports, thus acting as a drag on domestic real GDP. The fall in real GDP in 2021 induces a fall in the inflation rate, which is countered by an expansionary monetary policy. The resulting fall in interest rates contributes to a depreciation of the rupee, which further adds to inflationary pressures. Figure 7 illustrates these interlinkages of macroeconomic variables, following a fall in external demand and real domestic GDP. 


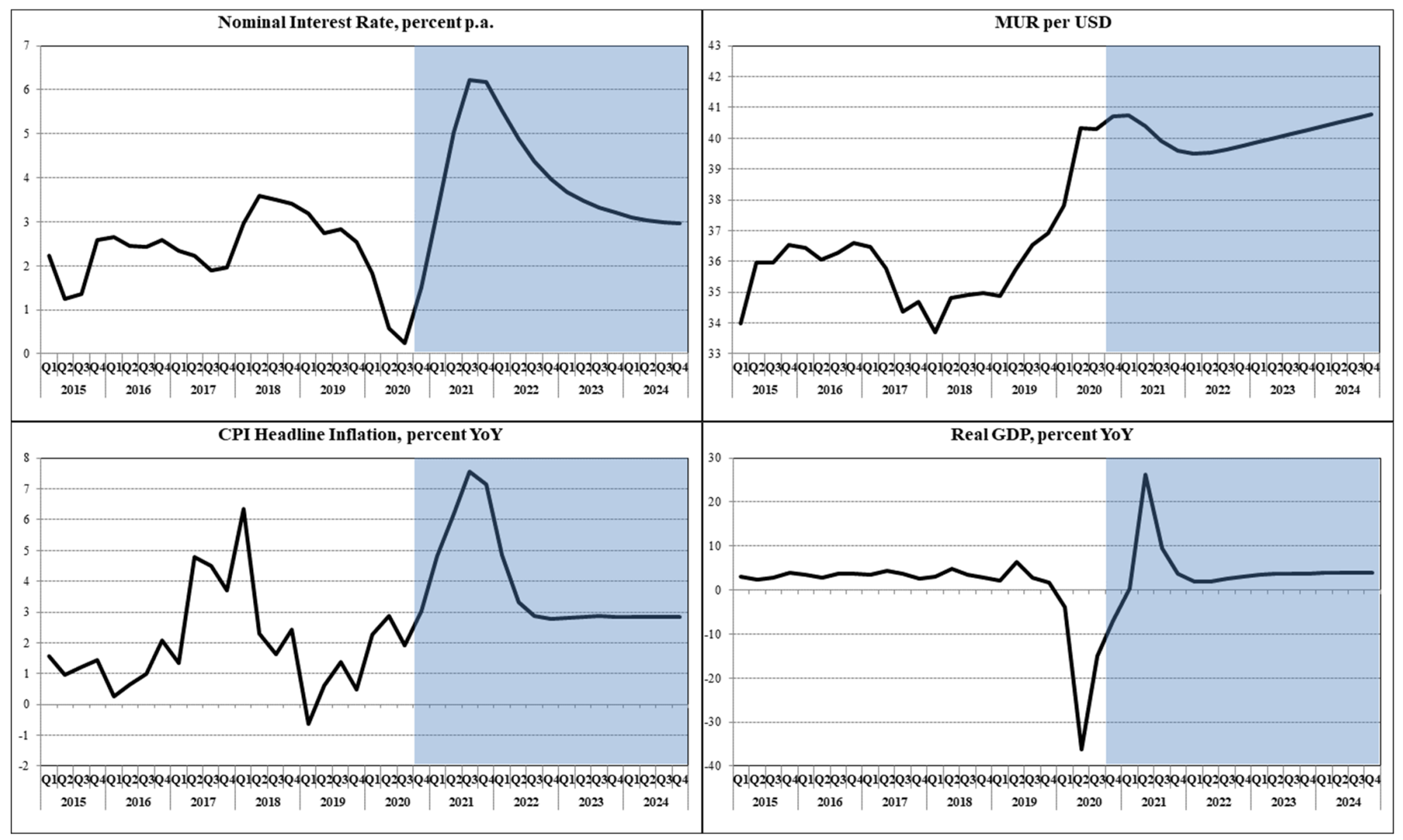

Figure 6. Food Price Shock.

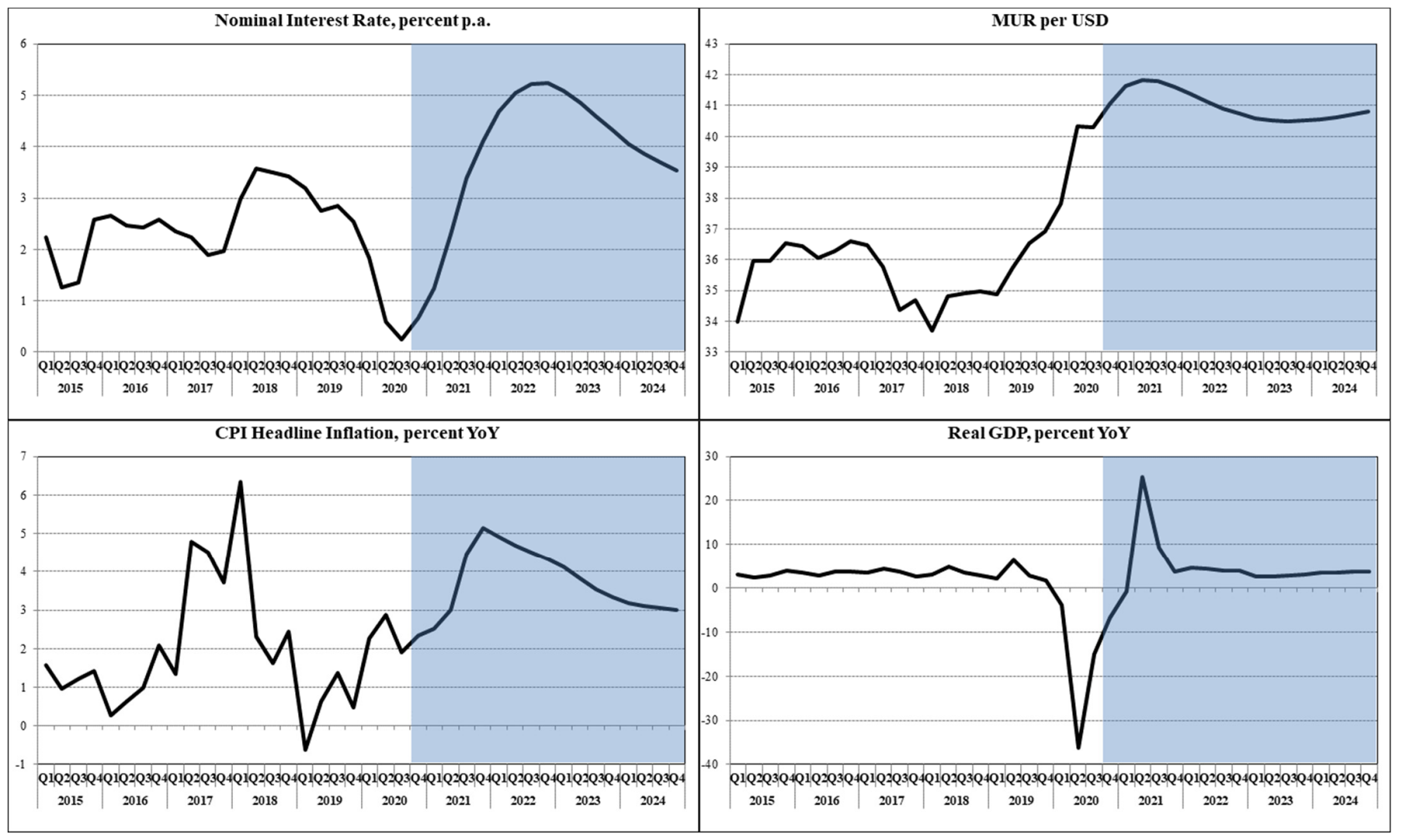

Figure 7. External Demand Shock. 


\section{Towards Inflation Targeting in Mauritius: Lessons to Be Learned}

Following the positive experiences of developed countries in inflation targeting over the past two decades, more emerging and developing countries are embracing inflation targeting as the preferred choice for a forward-looking monetary policy regime. It is of no surprise that the list of inflation-targeting countries drawn by Hammond (2012) has expanded over time.

The existence of numerous operational targets blurs the path within the monetary policy framework and does not suit an FFIT regime. In line with the prescriptions of Mishkin and Schmidt-Hebbel (2007) for a comprehensive inflation targeting framework, transitioning towards FFIT would require a number of changes to the monetary policy decision process in Mauritius. First, an explicit quantitative inflation target would need to be established as the medium-term objective. Legislation already accounts for the provision of a target but institutional commitment can be reinforced by holding the BOM more accountable for performance towards the attainment of the inflation objective. The shift to FFIT also implies that other goals of the central bank would need to be subordinated, with inflation remaining the sole objective. Although policy actions may appear to be effective in the near term, price trajectories would eventually reflect the impacts of excessively tight or relaxed monetary policies, highlighting inconsistencies in objectives in the long run. Contextually, the weights in the Taylor Rule equation would need to be revised towards the derivation of an optimal rule for Mauritius.

Sub-Saharan African countries have a tendency to adopt competing policy instruments such as interest and exchange rates (International Monetary Fund 2008). Transitioning towards a single inflation-targeting instrument is the premise behind a successful forwardlooking monetary policy regime. The role of the exchange rate in an open economy like Mauritius is subject to debate, as exchange rate movements can possibly weaken the inflation-targeting framework. Another school of thought favors exchange rate-anchored inflation targeting by pegging either the real exchange rate or the rate of nominal depreciation; this provides leeway for policymakers to conduct monetary policy. Buffie et al. (2018) argue that exchange rate management supports inflation targeting. Frequent interventions may make it more difficult for market participants to assess the objectives of foreign exchange intervention, thus hampering the credibility and effectiveness of monetary policy (Nordstrom et al. 2009). Transition to a full-fledged inflation targeting regime would therefore require clarity on both monetary and exchange rate policies to pave the way for a nominal anchor and reduce confusion regarding progress on achieving the inflation target.

At the outset, Mauritius has the essential attributes for successful transition to FFIT, as compared to its peers, due to the superior quality of its institutions that contributes to enhancing credibility. However, the choice of a nominal anchor remains obstructed because policymakers' attention is shifted to secondary objectives due by "the relatively shallow and unsophisticated nature of Mauritius's financial system, its history of sizable budget deficits, the thinness of its foreign exchange market, its limited integration into international capital markets, and its vulnerability to shocks" (Porter and Yao 2005). In this respect, the FPAS can enhance visibility and contribute substantially to forward-looking monetary policy formulation through baseline projections and scenario building for risk assessment.

Accountability and transparency of the central bank are the key ingredients required for a successful monetary policy formulation. Through appropriate institutional setting and political support, the role of forward-looking monetary policy can be enhanced and improved in Mauritius, thus eventually achieving policy credibility in a sustainable manner. This would involve communicating forecasts to the public and justifying deviations from inflation targets to members of parliament.

\section{Concluding Remarks}

Similar to other emerging countries practicing ITL, Mauritius exhibits the same difficulties in implementing forward-looking monetary policy. Achieving low and stable 
inflation consistently is indeed an accomplishment in emerging countries, where political interference and secondary policy targets can undermine the credibility of monetary policy. External shock vulnerability, rapid structural changes and the persistence of inflation reflected through market expectations can derail the drivers of growth. Successfully overcoming these challenges can, in principle, lie with an FFIT framework.

One key element that is required to support the transition to FFIT is a technically advanced economic forecasting tool. In this respect, the FPAS has been calibrated and tested for Mauritius. The model replicates well the monetary features in Mauritius and provides an array of technically advanced tools that can be used to assist in the monetary policy decision-making process. Unobserved trends of real exchange rate trend, real interest rate and potential output are key elements in the decision-making process. The FPAS framework facilitates the formulation of a forward-looking monetary policy by providing a baseline forecast, whilst also enabling a pro-active approach to monetary policy through scenario-building for economic risk assessment.

Since the inception of ITL, Mauritius has been able to stabilize inflation through decisive monetary policy actions. The present ITL framework already embraces elements that have been found to be critical for establishing an FFIT regime. However, the transition to FFIT provides value-added benefits to Mauritius. The growing literature shows that low inflation contributes to enhancing credibility. One of the inherent characteristics of FFIT is defining an explicit inflation target, which is pursued in the medium to long term. As a result, this is not limited to short-run actions aimed at output or any other secondary target. Inflation targeting, at least in the short run, is subject to limitations. A small open economy like Mauritius is subject to external shocks which affects the business cycle considerably. Should such a negative shock occur, a strict inflation targeting approach might not be appropriate. Furthermore, our model does not include an active role for fiscal policy. Indeed, in the real world, the interaction between monetary and fiscal policy is fundamental in determining macroeconomic outcomes. Consequently, it would be interesting to see how the model results would change, if the government, through automatic and discretionary measures, influenced market outcomes. We leave these limitations and considerations for further research.

Author Contributions: All authors take joint responsibility for the work presented here, including conceptualization, methodology, software, validation, formal analysis, investigation, resources, data curation, writing and visualization. All authors have read and agreed to the published version of the manuscript.

Funding: This research did not receive any specific grant from funding agencies in the public, commercial, or not-for-profit sectors.

Acknowledgments: The authors would like to thank the editor and the anonymous referees for their helpful comments and suggestions.

Conflicts of Interest: The authors declare no conflict of interest.

Disclaimer: The views expressed in this paper are those of the author(s) and do not necessarily represent those of the Central Bank of Mauritius. Any errors are the authors' responsibility.

\section{Appendix A. Alternative Specification of Phillips Curve}

The labor market is defined by the first four equations. The unemployment gap, $u_{t}$ is specified as the difference between the actual unemployment rate $U_{t}$ from the NAIRU $\bar{U}_{t}$ :

$$
u_{t}=\bar{U}_{t}-U_{t}
$$

The unemployment rate's stochastic process is defined through the following three equations, which, respectively, are subject to specific shocks.

$$
\bar{U}_{t}=\tau_{1} \bar{U}_{S S}+\left(1-\tau_{1}\right) \bar{U}_{t-1}+\overline{U G}_{t}+\varepsilon_{t}^{\bar{U}}
$$




$$
\begin{aligned}
& \overline{U G}_{t}=\tau_{2} \overline{U G}_{t-1}+\varepsilon_{t}^{\overline{U G}} \\
& u_{t}=\tau_{3} u_{t-1}+\tau_{4} y_{t}+\varepsilon_{t}^{u}
\end{aligned}
$$

Equation (A2) shows NAIRU consists of a time-varying trend $\overline{U G}_{t}$ and converges to its steady-state value $\bar{U}_{S S}$, which is determined exogenously. This time-varying trend $\overline{U G}_{t}$ allows it to be subject to shocks $\varepsilon_{t}^{\overline{U G}}$. Equation (A3) enables for a level of persistence in the difference of the NAIRU from its steady-state value. As for the foundation of Equation (A4), Okun's Law is used. This equation, through the output gap variable $y_{t}$, links deviations of the unemployment rate from the NAIRU to the level of slack in the economy.

Similarly, the block for the output gap is segmented as follows: observed output (real GDP in log terms) is decomposed into a trend $\left(\bar{Y}_{t}\right)$ and a gap component $\left(y_{t}\right)$ as in Equation (A5).

$$
Y_{t}=\bar{Y}_{t}+y_{t}
$$

As shown in Equations (A6)-(A8), the process for determination of output involves three separate shocks. The level of potential output grows at the rate of $G_{t}$, and is subject to a level shock $\varepsilon_{t}^{\bar{Y}}$. Assuming a coefficient of 1 for the AR term in (A6), including other things constant, a shock to the level of potential output has a permanent impact, lifting the path of potential output upwards or downwards in a parallel manner.

$$
\begin{gathered}
\bar{Y}_{t}=\bar{Y}_{t-1}+G_{t}+\varepsilon_{t}^{\bar{Y}} \\
G_{t}=\theta G^{S S}+(1-\theta) G_{t-1}+\varepsilon_{t}^{G} \\
y_{t}=\phi y_{t-1}+\varepsilon_{t}^{y}
\end{gathered}
$$

The potential growth rate $G_{t}$ also has a shock component $\varepsilon_{t}^{G}$. Notwithstanding any shocks, output increases at the constant steady-state growth rate of $G^{S S}$. A shock to the potential growth rate is temporary, leading output to adopt a higher growth rate, and permanently remaining at a higher level. However, the impact on the potential growth rate declines at the rate of $\theta$, indicating that higher values of $\theta$ lead to faster convergence to the steady-state growth rate. Contrary to shocks on the potential output and growth rate, output gap shocks do not involve a level shift of potential output. The effect of $\varepsilon_{t}^{y}$ can lead to temporary deviation of output from trend, but the output gap closes over time, with the convergence speed inversely proportional to $\phi$.

Finally, the Phillips Curve acts as a link between observed data on inflation and the unobserved output gap variable. See the Phillips Curve equation is below.

$$
\pi_{t}=\lambda \pi_{t+1}+(1-\lambda) \pi_{t-1}+\beta y_{t}+\varepsilon_{t}^{\pi}
$$

To overcome end-of-sample imprecisions, the model includes data on one-year ahead inflation and five-year ahead growth expectations.

$$
\begin{gathered}
\pi_{t+j}^{E}=\pi_{t+j}+\varepsilon_{t+j}^{\pi E}, j=0,1 \\
g_{t+j}^{E}=g_{t+j}+\varepsilon_{t+j}^{g E}, j=0, \ldots 5
\end{gathered}
$$

To allow for probable short-term deviations but eventual long-run convergence, expectations are incorporated into the model.

Bayesian Maximum Likelihood techniques are used to estimate the model. Parameter values and variances of error terms for the equations are estimated using Kalman filtering techniques. Blagrave et al.'s (2015) findings for emerging economies are applied as priors for parameter. In addition, the choice of steady-state parameters, that is, steady-state unemployment rates and growth rates of the Mauritius economy, are based on estimates derived through the application of the Hodrick-Prescott filter. The parameters are assumed 
to follow a truncated normal distribution with prior mean, $\mu^{*}$ and standard deviation $\sigma$, as specified in Equation (A6).

$$
\begin{gathered}
X_{i} \sim N\left(\mu_{i}^{*}, \sigma_{i}^{2}\right) \\
\mu_{i}^{*} \in\left[\mu_{i}^{L}, \mu_{i}^{U}\right]
\end{gathered}
$$

where $X_{i}$ is the vector of parameters to be estimated. Restrictions limit the distributions to values above $\mu^{L}$ and below $\mu^{U}$.

Given the data $Y$, and the corresponding data likelihood function $\mathrm{L}(\mu \mid Y)$, the model is estimated by regularized ML techniques. Following Ljung (1999), the posterior values for the parameters are derived as the optimisation solution of Equation (A13). The estimation process furthermore comprises the application of Kalman filtering techniques for the estimation of unobserved components.

$$
\operatorname{Max} \log \mathrm{L}(\mu \mid Y)-\sum \frac{\left(\mu^{*}-\mu\right)}{\sigma^{2}}
$$

\section{References}

Alichi, Ali. 2015. A New Methodology of Estimating the Output Gap in the United States. IMF Working Papers, No. WP/15/144. Washington, DC: International Monetary Fund (IMF).

Alichi, Ali, Kevin Clinton, Jihad C. Dagher, Ondra Kamenik, Douglas Laxton, and Marshall Mills. 2010. A Model for Full-Fledged Inflation Targeting and Application to Ghana. IMF Working Papers, No. WP/10/25. Washington, DC: International Monetary Fund (IMF).

Andrle, Michal, Andrew Berg, R. Armando Morales, Rafael Portillo, and Jan Vlček. 2013. Forecasting and Monetary Policy Analysis in Low-income Countries: Food and Non-Food Inflation in Kenya. IMF Working Papers, No. WP/13/61. Washington, DC: International Monetary Fund (IMF).

Aron, Janine, and John Muellbauer. 2007. Review of Monetary Policy in South Africa since 1994. Journal of African Economies 16: 705-44. [CrossRef]

Baldini, Alfredo, and Marcos Poplawski-Ribeiro. 2011. Fiscal and Monetary Determinants of Inflation in Low-Income Countries: Theory and Evidence from Sub-Saharan Africa. Journal of African Economies 20: 419-62. [CrossRef]

Barnichon, Régis, and Shanaka J. Peiris. 2008. Sources of Inflation in Sub-Saharan Africa. Journal of African Economies 17: 729-46. [CrossRef]

Batini, Nicoletta, Kenneth Kuttner, and Douglas Laxton. 2005. Does Inflation Targeting Work in Emerging Markets? In World Economic Outlook. Washington, DC: International Monetary Fund, pp. 161-86.

Berg, Andrew, Philippe D. Karam, and Douglas Laxton. 2006. A Practical Model-Based Approach to Monetary Policy Analysis-Overview. IMF Working Papers, No WP/06/80. Washington, DC: International Monetary Fund (IMF).

Bernanke, Ben. 1990. On the Predictive Power of Interest Rates and Interest Rate Spreads. NBER Working Papers, No 3486. Washington, DC: International Monetary Fund (IMF).

Blagrave, Patrick, Roberto Garcia-Saltos, Douglas Laxton, and Fan Zhang. 2015. A Simple Multivariate Filter for Estimating Potential Output. IMF Working Paper WP/15/79. Washington, DC: International Monetary Fund (IMF).

Bleaney, Michael, and Manuela Francisco. 2016. Inflation and Fiscal Deficits in Sub-Saharan Africa. Journal of African Economies 25: 529-47. [CrossRef]

Bleaney, Michael, Atsuyoshi Morozumi, and Zakari Mumuni. 2020. Inflation Targeting and Monetary Policy in Ghana. Journal of African Economies 29: 121-45. [CrossRef]

Buffie, Edward F., Marco Airaudo, and Felipe Zanna. 2018. Inflation targeting and exchange rate management in less developed countries. Journal of International Money and Finance 81: 159-84. [CrossRef]

Carare, Alina, and Mark R. Stone. 2006. Inflation Targeting Regimes. European Economic Review 50: 1297-315. [CrossRef]

Dizioli, Allan, and Jochen M. Schmittmann. 2015. A Macro-Model Approach to Monetary Policy Analysis and Forecasting for Vietnam. IMF Working Papers, No. WP/15/273. Washington, DC: International Monetary Fund (IMF).

Feldkircher, Martin, and Florian Huber. 2018. Unconventional U.S. Monetary Policy: New Tools, Same Channels? Journal of Risk and Financial Management 11: 71. [CrossRef]

Hammond, Gill. 2012. State of the Art of Inflation Targeting. In Handbooks. London: Centre for Central Banking Studies, Bank of England, vol. 4.

Heerah-Pampusa, Marjorie, Waësh Khodabocus, and Vandana Morarjee. 2006. A Primer on Inflation. Bank of Mauritius Occasional Papers, No 1. Port Louis: Bank of Mauritius.

Heintz, James, and Léonce Ndikumana. 2011. Is there a Case for Formal Inflation Targeting in Sub-Saharan Africa? Journal of African Economies 20: ii67-ii103. [CrossRef]

Holmes, Mark J. 2002. The Inflationary Effects of Effective Exchange Rate Depreciation in Selected African Countries. Journal of African Economies 11: 201-18. [CrossRef] 
International Monetary Fund. 2008. Monetary and Exchange Rate Policies in Sub-Saharan Africa. In Regional Economic Outlook, Sub-Saharan Africa. Washington, DC: IMF, Chapter 2.

Islam, Faridul. 2019. Currency Crises: Are There Signals to Read? Journal of Risk and Financial Management 12: 128. [CrossRef]

Khoury, Sarkis Joseph, and Poorna C. Pal. 2020. Negative Interest Rates. Journal of Risk and Financial Management 13: 90. [CrossRef]

Laxton, Douglas, David Rose, and Alasdair M. Scott. 2009. Developing a Structured Forecasting and Policy Analysis System to Support Inflation-Forecast Targeting (IFT). IMF Working Papers, No WP09/65. Washington, DC: International Monetary Fund (IMF).

Ljung, Ljung. 1999. System Identification: Theory for the User. Upper Saddle River: Prentice-Hall.

Madhou, Ashwin, and Tayushma Sewak. 2019. Eamining Structural Unemployment in Sub-Saharan Africa: Empirical Evidence from Unobserved Components. Open Economies Review 30: 895-904. [CrossRef]

Mishkin, Frederic S., and Klaus Schmidt-Hebbel. 2007. Does Inflation Targeting Make a Difference? NBER Working Papers, No. w12876. Cambridge: National Bureau of Economic Research, Inc.

Morozumi, Atsuyoshi, Michael Bleaney, and Zakari Mumuni. 2020. Inflation targeting in low-income countries: Does IT work? Review of Development Economics 24: 1529-50. [CrossRef]

Nordstrom, Anna, Scott Roger, Mark R. Stone, Seiichi Shimizu, Turgut Kisinbay, and Jorge Restrepo. 2009. The Role of the Exchange Rate in Inflation: Targeting Emerging Economies. IMF Working Papers, No 267. Washington, DC: International Monetary Fund (IMF).

O'Connell, Stephen A. 2011. Towards a Rule-based Approach to Monetary Policy Evaluation in Sub-Saharan Africa. Journal of African Economies 20: ii36-ii66. [CrossRef]

Peiris, Shanaka J., Ding Ding, and Rahul Anand. 2011. Toward Inflation Targeting in Sri Lanka. IMF Working Papers, No. WP/11/81. Washington, DC: International Monetary Fund (IMF).

Porter, Nathan, and James Y. Yao. 2005. Inflation Targeting Lite. In Small Open Economies: The Case of Mauritius. Washington, DC: International Monetary Fund, vol. 5.

Saman, Corina, and Bianca Pauna. 2013. New Keynesian Phillips Curve for Romania. Journal of Economic Forecasting 2: $159-71$.

Tsangarides, Charalambos G. 2010. Monetary Policy Transmission in Mauritius Using a VAR Analysis. IMF Working Papers, No WP/10/36. Washington, DC: International Monetary Fund (IMF).

Xu, Lei, Takuji Kinkyo, and Shigeyuki Hamori. 2018. Predicting Currency Crises: A Novel Approach Combining Random Forests and Wavelet Transform. Journal of Risk and Financial Management 11: 86. [CrossRef] 